\title{
Epilepsy in children and the risk of drowning
}

\author{
Alison M Kemp, J R Sibert
}

\begin{abstract}
To clarify the risks of drowning for children with epilepsy we have studied the records of the $\mathbf{3 0 6}$ children who drowned or nearly drowned in the UK in 1988 and 1989. Ten children with incidents related to epilepsy presented over the study period, four of whom drowned. Children with epilepsy had a higher incidence of submersion accidents but no child participating in supervised swimming drowned. Two children died in the bath. Five children had special needs.

We conclude that children with epilepsy can enjoy swimming with a friend in a lifeguard supervised swimming pool. They should be encouraged to shower in a non-glass cubicle rather than have a bath. The bathroom should remain unlocked. Children with poorly controlled epilepsy or associated learning difficulties are at a higher risk from all accident trauma. They need a very high level of supervision while swimming and advice should be given on an individual basis according to what is considered realistic for that child.

(Arch Dis Child 1993; 68: 684-685)
\end{abstract}

The potential dangers of swimming and bathing to children with epilepsy after a seizure are acknowledged. The extent of the problem and the advice that should be given to these children however remains unclear. We have studied the risk of drowning and near drowning in these children as part of a study of the problem as a whole in the UK, ${ }^{12}$ examining features of both the accident and the child with epilepsy that might contribute to the submersion incident. We outline the advice that we feel should be given to children with epilepsy and their families regarding water safety.

\section{Methods}

We studied children under 15 years of age in the UK who drowned or nearly drowned in the years 1988 and $1989 .{ }^{1}$ Drowning deaths were notified through the Office of Population Censuses and Surveys and the central statistic offices in Scotland and Northern Ireland. Case details were extracted from the coroners' records in England and Wales and the procurators fiscal in Scotland. Cases of near drowning were notified through the British Paediatric Surveillance Unit (BPSU) inquiry system, to which consultant paediatricians throughout the British Isles return monthly notification cards for a series of rare conditions. Details of each case were obtained from a questionnaire completed by the admitting paediatrician and from retrospective analysis of hospital case records. ${ }^{12}$

From this information we identified children with epilepsy using the definition of an afebrile seizure from the International League against Epilepsy': 'paroxysmal disturbance of consciousness, sensation, or movement primarily cerebral in origin, unassociated with acute febrile episodes'.

This definition was used by Verity et al who studied epilepsy in the first 10 years of life in children from the 1970 British births survey. ${ }^{4}$ They quote an incidence of 4.3 per 1000 for children who have a history of active epilepsy in the first 10 years of life.

\section{Results}

Three hundred and six submersion incidents were notified to the study (157 near drowning cases and 149 drowning deaths). Twelve (4\%) incidents followed an epileptic seizure. Five of these children died, one of whom was a 13 year old boy who had had his first epileptic fit while in
Department of Child Health, University of Wales College of Medicine, Community Health Unit, Lansdowne Hospital, Cardiff CF1 8UL Alison M Kemp J R Sibert Correspondence to: Professor Sibert.

Accepted 20 January 1993
Table 1 Details of the 10 children with epilepsy who experienced a submersion incident

\begin{tabular}{|c|c|c|c|c|c|}
\hline $\begin{array}{l}\text { Subject } \\
\text { No }\end{array}$ & $\begin{array}{l}\text { Age } \\
\text { (years) }\end{array}$ & Sex & Details of epilepsy & Accident site & Outcome \\
\hline $\begin{array}{l}1 \\
2\end{array}$ & $\begin{array}{l}3 \cdot 5 \\
6\end{array}$ & $\mathbf{F}$ & $\begin{array}{l}\text { Normal child, } 3-4 \text { fits in life } \\
\text { Cerebral palsy, quadriplegic, poor } \\
\text { epilepsy control }\end{array}$ & $\begin{array}{l}\text { Bath, left alone } \\
\text { Hydrotherapy pool, poor } \\
\text { resuscitation facilities }\end{array}$ & $\begin{array}{l}\text { Drowned } \\
\text { Drowned }\end{array}$ \\
\hline 3 & 9 & $\mathbf{F}$ & Cerebral palsy, poor epilepsy control & $\begin{array}{l}\text { Bath, left alone, resuscitated, } \\
\text { admitted hospital }\end{array}$ & Died of ARDS \\
\hline 4 & 13 & $\mathbf{M}$ & $\begin{array}{l}\text { Normal child, epilepsy for } 2 \text { years, } \\
\text { fits every } 6 \text { weeks }\end{array}$ & Swimming alone in flooded quarry & Drowned \\
\hline 5 & $1 \cdot 7$ & $\mathbf{F}$ & $\begin{array}{l}\text { Normal child, epilepsy since birth, } \\
\text { recent treatment stop }\end{array}$ & Domestic pool, resuscitated & ITU, full recovery \\
\hline 6 & 12 & $\mathbf{M}$ & Austic child, weekly fit & Public pool, prompt resuscitation & $\begin{array}{l}\text { ITU, pulmonary oedema, full } \\
\text { recovery }\end{array}$ \\
\hline 7 & 14 & $\mathbf{F}$ & $\begin{array}{l}\text { Normal child, photoconvulsive } \\
\text { epilepsy for } 18 \text { months }\end{array}$ & Public pool, prompt resuscitation & ITU, pneumonia, full recovery \\
\hline 8 & 9 & $\mathbf{M}$ & Normal child, fit control unknown & Public pool, prompt resuscitation & $\begin{array}{l}\text { ITU, } 3 \text { days' ventilation, full } \\
\text { recovery }\end{array}$ \\
\hline 9 & 12 & $\mathbf{F}$ & $\begin{array}{l}\text { Moderate learning difficulties, poor } \\
\text { fit control }\end{array}$ & Public pool, prompt resuscitation & $\begin{array}{l}\text { ITU, pulmonary oedema, full } \\
\text { recovery }\end{array}$ \\
\hline 10 & 7 & $\mathbf{M}$ & Normal child, poor fit control & Paddling in sea, prompt resuscitation & Full recovery \\
\hline
\end{tabular}

ARDS = acute respiratory distress syndrome; ITU = intensive therapy unit. 
Table 2 Water safety recommendations for children with epilepsy

Swimming
- Swim with a friend
- Swim in a supervised swimming pool. Supervisor should be
trained in cardiopulmonary resuscitation and fully aware of
child's epilepsy
- Avoid open waterway swimming
Bathing
- Encourage children to shower in a hand held shower and not in
a glass cubicle to reduce trauma in the event of a fit
- Bathtime supervision of the young child with epilepsy is
- essential
- Shower in an unlocked room
Poorly controlled children with epilepsy
- High level of adult supervision while swimming
- Bathe seated in bath, plug out, and hand held shower
- Encourage mother with epilepsy to be accompanied while
bathing baby or toddler

the bath. One child, known to have epilepsy nearly drowned, the incident was not however fit related. In addition a baby drowned in the bath when her mother who had epilepsy had a fit.

Ten cases met the criteria of established epilepsy. All suffered tonic-clonic seizures and had been on anticonvulsant medication. No child suffered a submersion accident as a result of a febrile convulsion. The male:female ratio was $2: 3$ in contrast to the $3: 1$ ratio in the overall study. Details of the accident and the child are shown in table 1 .

\section{Discussion}

None of the children with primary epilepsy who were supervised at the time of the accident died, suggesting that if epileptic children are supervised they have no greater risk of a drowning death than the general population.

This study suggests that a child who suffers from epilepsy is 7.5 times more likely to experience a submersion incident than a child without epilepsy. Direct comparison of the literature is difficult because of the number of variables involved. Orlowski et $a l^{5}$ combine their figures with those from five other reported studies. ${ }^{6-10}$ They state that children with epilepsy are four times more likely to drown than those without epilepsy. They quote a $1 \%$ incidence of epilepsy in the child population in contrast to our figure of $0.43 \%$; our results are therefore in line with these studies.

The extent of exposure of children with epilepsy to water is unknown, some are excluded from swimming by parents or cautious medical advice. Risk calculations are at best an approximation, but using $0.43 \%$ as the prevalence figure for children with a history of epilepsy, among 306 cases of submersion 1.3 children would be expected to suffer from drowning incidents related to epilepsy, whereas we ascertained 10 cases.

Four of the six children with epilepsy nearly drowned in public swimming baths. They had all received prompt resuscitation and made a full recovery. We recognised the good safety record of these lifeguard supervised swimming pools ${ }^{1}$ in our overall study. In contrast two of the four fatalities occurred in the bath. The overall mortality rate for bath submersion incidents in children is high. In the overall study $56 \%$ of the children who suffered submersion accidents in the bath died. ${ }^{1}$ The dangers of drowning in the bath to patients of all ages with epilepsy are well known. ${ }^{11}$

Two children who died had severe learning difficulties in association with cerebral palsy. An increased mortality rate in children with epilepsy with associated mental retardation is well recognised. ${ }^{12}$ They are more prone to all types of accidental trauma. In our overall study $4.5 \%$ of the children had moderate to severe learning difficulties $70 \%$ of whom died. ${ }^{1}$

Children with epilepsy should enjoy a normal childhood developing skills with their peer group. Our study shows that they can participate safely in supervised recreational swimming. Unsupervised swimming and swimming in open waterways should be discouraged. Children who have a fit in water disappear below the surface quickly and silently during the tonic phase of a fit. ${ }^{5}$ Rescue is easier from the clear, relatively shallow waters of a swimming pool than from the murky, uncharted depths of open waterways.

Children with special needs and epilepsy and those with poorly controlled fits are at a higher risk of submersion accidents. They need particularly careful supervision and attention at all times. Every child's epilepsy is different. Advice should be given in line with what is considered realistic given the child's particular circumstances.

Table 2 outlines recommendations for parents of children with epilepsy for swimming and at bath time.

The authors thank the BPSU and paediatricians nationwide.

1 Kemp AM, Sibert JR. Drowning and near drowning in children; lessons for prevention. BMF 1992; 304: 1143-6. Kemp AM, Sibert JR. Outcome for children who nearly drown: a British Isles study. BMF 1991; 302: 931-3.

3 The Commission on Classification and Terminology of the International League against Epilepsy. Proposal for the revised clinical and electroencephalographic classification of epileptic seizures. Epilepsia 1981; 22: 489-91.

4 Verity CM, Ross EM, Golding J. Epilepsy in the first 10 years of life: findings of the child health and education study. $B M \mathcal{F}$ 1992; 305: 857-60.

5 Orlowski JP, Rothner AD, Leuders H. Submersion accidents in children with epilepsy. Am $\mathcal{F} D$ is Child 1982; 136: 777-80.

6 Pearn JH. Epilepsy and drowning in children. BMF 1977; $\mathrm{i}$ : 1510-1.

7 Pearn JH, Bart R, Yamaoka R. Drowning risk to epileptic children: a study from Hawaii. BMF 1978; ii: $1284-6$.

8 Adams AI. The descriptive epidemiology of drowning accidents. Med F Aust 1966; ii: 1257-61.

9 Chun B, Okihiro MM, Hale RW. An analysis of drowning incidents in Oahu. 1960-1970. Hawaii Med $\mathcal{f}$ 1973; 32: 92-5.

10 Dietz PE, Baker SP. Drowning: epidemiology and prevention. Am f Public Health 1974; 64: 303-12.

11 O'Donohoe $\mathrm{N}$. What should the child with epilepsy be allowed to do? Arch Dis Child 1983; 58: 934-7.

12 Williams CE. Accidents in mentally retarded children. Dev Med Child Neurol 1973; 15: 660-2. 